\title{
Climate Change Adaptation: Services and Role of Information Communication Technology (ICT) in India
}

\author{
Anup Prakash Upadhyay, Arvind Bijalwan* \\ Indian Institute of Forest management, Nehru Nagar, Bhopal, Madhya Pradesh, India
}

Email address:

arvindbijalwan276@gmail.com (A. Bijalwan)

\section{To cite this article:}

Anup Prakash Upadhyay, Arvind Bijalwan. Climate Change Adaptation: Services and Role of Information Communication Technology (ICT) in India. American Journal of Environmental Protection. Vol. 4, No. 1, 2015, pp. 70-74. doi: 10.11648/j.ajep.20150401.20

\begin{abstract}
Changing climate is one the most challenging issue that humankind is facing and its intensity seems to be more throbbing in the time to come. In order to overcome the alarming situation of climate change, mitigation and adaptation are two alternatives. On one hand, the mitigation is gradual and long term process however on other adaptation is usually based on quick responses to the changing scenario. Adaptation requires effective and timely delivery and exchange of all supporting mechanism and meteorological information, thus successful adaptation to climate change necessitate the Information Communication Technologies (ICT) to disseminate the information in multifarious ways. ICT not only reduce the time lag but also systemically transform the information through networked governance. ICTs can play a crucial role in supporting public outreach, building a data base, creating awareness for the adaptation against the impact of climate change and thus secure well being of biophysical entities.
\end{abstract}

Keywords: Climate Change, Information Communication Technologies (ICT), Adaptation, Mitigation, Climatic Aberration, Geography, Biophysical Entities

\section{Introduction}

Climate change, a comprehensive global environmental changes in the behaviour of climate in recent and distance past likely to have lethal effects on biophysical entities that can lead to critical mark on the survival of human being. The impact of climate change is undoubtedly being felt by the entire globe; however, the scenario in India seems to be comparatively pertinent due to varying geography and anthropogenic pressure. The situation, such as abnormal fluctuation in temperature (low and high), erratic rain fall (pattern and distribution), drought, flood etc are the witness of climatic aberration leading to series of problems in the survival and existence of the human being.

The consequences of climate change in India can be observed in all the sectors; however the fluctuation in time of flowering pattern in the plants (early and late), rising trend of unpredictable disease in animals including human being and shifting agricultural cropping pattern and sequences are some of them. Take an example of one of the prominent sector (agriculture) of India basically includes crop husbandry, animal husbandry, horticulture and fisheries, experiencing vagaries in climatic parameters particularly, rise in temperature and erratic rainfall pattern making agriculture to more vulnerable. The emerging situations like drought to flood in the agricultural fields and chilling to heat energies in crops and animals making the toppling state of Indian agriculture. It is very much evident that the major impacts of climate change will be on agricultural and food systems over the next few decades [1]. However application of crop modeling tools, have pointed out that climate change is likely to reduce food availability due to a reduction in agricultural production [2].

Now there is a unified voice from the scientific community, policy makers and common man of the country to develop proper adaptation and mitigation mechanism against changing climatic parameters. In order to overcome the alarming situation of climate change, adaptation and mitigation are two options. Adaptation is said to be older than Mitigation. Various strategies of adaptation to climate change have been employed throughout the history, while mitigation initiatives have evolved only when the scientific community reached on a conclusion and determined a possible interaction between human actions and climate. There is uncertainty in the exact intensity and impact of climate change because of complex interaction in ecosystem, improper feedback. 


\section{Climate Change Adaptation}

Adaptation to climate change can be expressed as a finetuning with ecological, economic and social systems in response to observed or expected changes in climatic stimulus and their effects [3], moreover, adaptation can also explained as a set of approaches and actions taken by human in anticipation to the changing climate (acclimatization). Hence adaptation is a constant flow of activities, performance, choice and approaches that report to decisions about all aspects of life and that reflects existing social norms and processes [4]. Though, mitigation is equally important, however it is long term strategy and the real beneficiaries of mitigation will be the coming generations.

The adaptation is a great deal toward the minimizing the impact of climate change and as quick as needed in the present time. For example, remote sensing techniques have been used for environmental monitoring purposes, decision support tools and information and advisory system have been designed to guide users in the planning and implementing adaptation processes. In country like India the knowledge about adaptive ability of dry land farmers, forest dwellers, fisher folk and nomadic shepherds is very low [5] which directly hit such poor communities. There are two main practices of adaptation; autonomous and planned adaptation, the autonomous adaptation is mainly triggered by ecological changes in natural systems whereas planned adaptation is the result of a deliberate policy decision, creation of awareness and applying tools of adaptation [3]. There is an important need to compare the cost and benefits of adaptation strategies for making equilibrium among the society, further, if adaptation to climate change could be carried out at negligible cost then it may be less expensive, at least in the short-term, than any alternate strategy [6].

The task of adaptation to the impact of climate change in India requires wide spread knowledge, awareness and their communication not only to the scientific and administrative community but also to the common man's level. There are countless effects likely to be projected for climatic vagaries, however, these effects are weakly understood and our projections to climate change are still not very comprehensive and communicative. The factual impact of climate change in Indian is difficult to predict that too becomes more complex in diverse agro-ecological regions. Adaptation is the major corridor to pass through Indian situation for the sustenance in future. The sharing of information of adaptation to the common man is the success for fighting against climate change, yet the question is remaining same as how to disseminate the techniques and technology to the last man standing on the row. In this context, Information Communication Technologies (ICT) is being helpful to disseminate the knowledge of adaptation for fighting against climate change. TCT is a wide term which refers to all computer-based advanced technologies for managing and communicating information. In a literal sense it is broader than Information Technology (IT). It is the study, design, development, implementation, support or management of computer-based information systems, particularly software applications and computer hardware.

In the current scenario, ICTs not as such playing fullfledged role in the climate change sector however ICT has been applied in the study of the issue of climate change, but the application of ICTs in the adaptation and mitigation domains is yet to explore its full potential. As many international analysts noticed, ICT is greatly absent in this field, especially if we separate the systems based information management (such as Information Systems) from the technologies that are more oriented to communication services [7]. The World Telecommunication Development conferences, in 1998, 2002 and in 2006 [14-16] invited the Telecommunication Development Sector, in general, and the Telecommunication Development Bureau in particular, to assist developing countries in the use of information and communication technologies for the protection of the environment. For climate change there could be various reasons, but the major concern is man-made climate change as it is leading to gradual increase in warming of planet at an alarming rate.

It has been perceived that yesterdays backward nation were those who missed industrial revolution but tomorrows backward nation will those who will be missing communication revolution. ICT has revolutionised the whole world. Now when India is regarded as hub of the ICT every sector in the country is talking of using ICT. However efforts in this direction are state specific while a centralized approach is advocated to avoid duplication of efforts and to maintain uniformity and compatibility. ICT has shown immense potential in almost the entire prime sectors; be it medical, agriculture, Science and Technology etc., however, environmental issues also can't remain in isolation and untouched. ICT has vast potential and its potential could be utilised in combating the problems of environment and changing climate. It has untapped potential in this sector [8]. ICT has already been used in various countries in various forms ranging from cutting down the emissions to developing a data base of change occurring. It is being used in satellite communication to provide weather forecast, terrestrial systems that are also used for dissemination of information concerning different natural and man-made disasters (early warning), atmosphere composition data base, Ocean parameters etc. Till date use of ICT, climate change adaptation, mitigation and sustainable development has largely focused on ICT industry audience and its larger scope is still not much discussed. The ICTs have the potential to strengthen long-term adaptation strategies, decision-making processes, raising awareness, capacity building and participation, among other areas [9].

The situation at present is argued as ICTs provide generic support to the process of information gathering, decision making, implementation and evaluation for national level adaptation. Specific ICT applications have enough potential to enable delivery of particular adaptation actions for the threat being imposed by climate change. Moreover, knowledge and information can play a key role in 
overcoming constraints. Timely information and awareness are pivotal for building and strengthening the capacity of multiple stakeholders involved in adaptation strategies at the micro, meso and macro levels. ICTs, the Internet based applications, mobile phones, telecentres, community radio, etc those are increasingly available in developing regions like India posses an exceptional potential and provides opportunity to improve the creation, management, exchange and application of relevant climate change information and knowledge.

The climate change adaptation could be in two ways viz. planned and spontaneous. One possible assumption says it could be planned another is emergent. While the latter refers to spontaneous actions taken by people affected by climatic change or the events led by climate change, planned or policy driven adaptation processes involve the formulation of strategies that consist of a general plan of action, including policies and measures, for addressing climate change impacts within a given context. As many other developing countries, India is facing significant challenges linked to the increasing intensity and frequency of climate change related events. India with a rapidly expanding ICT industry and a advanced telecommunications sector, has been a pioneer in the exploration of ICTs as key tools towards the achievement of adaptation goals of climate change.

ICT potential as it has been discussed widely and yet many things to be done to harness the full potential of ICT in the field of climate change adaptation. There are certain issues which has major bearing on the role of ICT in climate change adaptation that too when this adaptation has to be a planned one [10]. Adaptation takes place at all levels in society may it be large-scale interventions which are generally driven by governments and regional organizations or the autonomous actions taken by threatened communities and individuals. In a study [11] mentioned that aappropriate adaptation in climate change requires:

- Access to current information and understanding of the physical and socio-economic changes along with the potential changes and effects which are or could occur as a result of climate change

- Appropriate adaptation calls for design and implementation of effective responses mechanism to the challenges posed by climate change or potential challenges and opportunities arising from climate change

- Coordinated action by all stakeholders at all levels in synchronous fashion, including those at the local level

- Reliable information and appropriate guidance on actions that may be or likely to be taken to increase the resilience of vulnerable.

Human skills are just as essential to the application of ICTs for adaptation as infrastructure, equipment and applications. ICTs can play a crucial role in supporting public outreach and building awareness of the impact of climate change and adaptation, as well as offering opportunities to address those challenges. To analyze the role that ICTs can play in supporting top-down and bottom-up approaches to adaptation, as well as the development of new arrangements for changing pattern of global governance and assessing the local and national responses to climate change, it is necessary to use a framework found in much of the current literature on the relationship between ICTs and the environment. In a study conducted about strategic use of ICT [12] in various sectors such as Social, rural development, Sustainable natural resource management the same is possible to apply with the three main functions of ICTs to the development of an adaptation strategy for climate change. First, data collection is important for constant monitoring of the climate system. Second, it is important to have tools for processing data and information which will be guiding the people in the analysis, planning and implementation of possible adaptation strategies. Finally, strategic communication tools are needed to manage the adaptation process and build on the knowledge which is generated within and outside the given system. Based on the current and similar kind of literature ICT application in climate change adaptation could significantly be categorized in three distinguished categories.

\section{Direct Role of ICT}

The use of ICTs can be for assessing the effect of climate change by developing a data base. This data base could be utilized for monitoring and measuring climate change, measuring the effects of climate change and controlling the level of interactions with the environment (e.g., the Internet of Things, monitoring and measurement of climate change impacts, the impact of weather/ climate on natural resources such as water sea levels, annual rainfall and weatherdependent economic sectors such as agriculture, horticulture, forestry, fisheries, and the potential impact of climate change on health related issue which could be of long term in nature).

\section{Indirect Role of ICT}

ICT is and can act as medium for mass communication. It could continue doing so in the field of climate change with a lot of efficiency. The ICTs could be used as a medium for increasing awareness and facilitating dialogue about the effects of climate change. It could be utilized for creating mass awareness and developing sensitivity among masses for climate change and responsible factors for climate change (e.g., Web 2.0 and social networking applications, earlywarning systems concerned particularly with acute events resulting from climate variability and climate change).

\section{System Based Role of ICT}

The ICTs could find a new role in the changing economic and social organization as enabler for networked governance. The new forms of economic and social organization and decision-making that will likely be needed not only to adapt to climate change, but to achieve sustainable development (e.g., the kinds of Internet-based, open organizations and decision-making processes, transmission of information as well as guidance to and between local communities with reference to impacts that they may experience due to climate 
change, expert advice system which could tell people about actions that they could take to protect themselves against sudden weather-induced crises, and potential lifestyle along with behavioral changes that will help to secure lives and livelihoods in the longer term).

Understanding local situation the ecosystem itself and its social and cultural environment is very much important if adaptation interventions are to be successful. In general keeping other factors constant current uses of ICTs in the context of climate change may achieve the objectives of generating, organizing and communicating information about the risks resulting from climate change, climate variability and extreme climate events, as well as preparing for their effects on food security and water supply.

ICT for climate change adaptation may help in developing information systems within the food sector that are better able to reflect household access to food and food consumption. ICT could prove to be a great asset in developing early warning and hazard risk information systems to deal with the additional fire hazards associated with climate change and to enable integrated fire management; and developing ICT mapping tools to map vulnerable areas and provide spatial representations of climate change impacts.

These practical applications use a wide variety of technologies which are interconnected using existing communications networks and services, including:

- High-value remote monitoring equipment such as satellites

- Networks of remote sensors

- Global positioning and GIS applications

- Communications services such as the internet, mobile networks and SMS

- Handheld devices such as mobile phones and PDAs.

\section{Challenges Ahead}

ICT as it has been quoted in various literature, itself a major factor responsible for climate change. The intensity of ill effect of ICT is found lesser than the positives which could be derived by use of ICT for climate change adaptation. But the fact is above quoted statement lacks substantial evidence. It becomes itself a challenge for establishing ICT as a tool for climate change adaptation. Besides it is very much evident that building the capacity for integrating ICTs into adaptation policy development will have significant benefits, if particular attention is being paid to including more detailed application of ICTs in National Adaptation Plans. For a successful employment of ICT at the community level it is essential to frame strategy within Communication for Development this strategy which meant to be as the systematic application of processes, strategies and principles of Communication aimed at bringing positive social change itself is a big challenge in South Asia which have so much of diversity [13].

Engagement of the ICT private sector in climate change adaptation is less substantial and widespread phenomenon till today. It is more in use in climate change mitigation policy, where the private sector is directly involved in developing clean technologies, energy efficiency, dematerialization to reduce carbon footprints and various other areas of innovation. There is need to do more work to engage private ICT sectors/players strategically to review where privately motivated interests in applications would directly or indirectly enhance adaptation while also delivering commercial value. Identifying a public private partnership platform for integration mechanism to combat the issues of climate change and facilitate adaptation itself is a big challenge.

Another challenge in establishing and utilizing ICT potential for climate change adaptation is in making the use of ICTs embedded in the adaptation planning processes. This step is already being taken up at global level by most of the countries. Preparation for these should include a capacity building programme to review where and how investments in ICTs might be best integrated within these plans need to be decided. In India most of the ICT-related interventions that have taken place in last decade or so are either at a macro or a micro level. When we say macro level use of ICT for climate change adaptation it resembles with the intergovernmental dialogue, national strategies related with the use of ICT for climate change monitoring system, largescale projects specifically meant for weather monitoring by satellite and large-scale sensor networks. Micro level ICT use for climate change adaptation programmes or projects aimed at increasing awareness and information for vulnerable communities and individuals. This awareness creation is done with assumption that it will help people identify and manage their own adaptation needs. There is a lack of the meso level use of ICT for climate change adaptation which is the need of the hour in bridging the gap between grand strategies having a national level perspective and local circumstances which are very much regional in nature.

\section{Conclusion}

ICTs as of today in the country like India have not yet become effectively integrated into adaptation planning when the issue of climate change adaptation is discussed. The potential of ICT-related interventions is insufficiently explored. When we say ICT for climate change adaptation we need reliable, high quality communications infrastructure which will ensure the effective use of ICTs. This ICT-enabled creative capacity is one of the keys to adapting to the consequences of climate change, particularly in the most vulnerable regions of India in which areas that are geographically, economically or socially marginal, and therefore tend to lie at the edges of mainstream concerns. Linking successful ICT pilots with farmer field schools may be one way of providing information and agro-advisory services. This could include those related to climate and building capacity on a wider scale. Such approaches enhance the understanding of farmers' needs as it has bottom up orientation and thus help redress and improve the existing 
situations for delivering agro-met services.

As it has been discussed that how ICT can play its role in climate change adaptation the point here to understand is technology can only deliver services and applications if that underlying infrastructure is available. It needs strengthening across the country in terms of infrastructure and capacity building. ICTs can play a crucial role in supporting public outreach, building a data base, creating awareness of the impact of climate change and adaptation, suggest possible interventions based on the data base for adaptive mechanism as well as ICT can offer opportunities to address those challenges.

\section{Acknowledgement}

The authors are thankful to the Director, IIFM, Bhopal, India for encouragement and the anonymous reviewers for improving the quality of this manuscript.

\section{References}

[1] Brown, Molly E. and Funk, Christopher C. (2008). Food Security under Climate Change. Science; Vol. 319, no. 5863, pp. 580-581.

[2] Lobell, David B.; Burke, Marshall B.; Tebaldi, Claudia; Mastrandrea, Michael D.; Falcon, Walter P.; Naylor, Rosamond L. (2008). Prioritizing Climate Change Adaptation Needs for Food Security in 2030. Science; Vol. 319, no. 5863, pp. 607-610.

[3] IPCC (2007). Fourth Assessment Report - Climate Change: Synthesis Report, 2007.

[4] Daw, T., Adger, W. N., Brown, K., and Badjeck, M. C. (2009). Climate change and capture fisheries: potential impacts, adaptation and mitigation. In: Climate change implications for fisheries and aquaculture overview of current scientific Knowledge, Cochrane, K., Young, C. De, Soto, D., \& Bahri, T. (Eds). FAO Fisheries and Aquaculture Technical paper: No. 530, pp.107-150, FAO, Rome.

[5] Ravindranath, N. H. and Sathye, J. (2002). Climate Change and Developing Countries, Kluwer Academic Publisher, Dordrecht, Netherland.

[6] Sathaye, J., Shukl, P.R. and Ravindranath, N.H. (2006). Climate Change, Sustainable development and India: Global and national concerns. Current Science, 90 (3), 314-325.

[7] Sala, S. (2009). Information and communication technologies for climate change adaptation, with a focus on the agricultural sector. Thinkpiece for CGIAR Science Forum Workshop on "ICTs transforming agricultural science, research and technology generation," Wageningen, Netherlands. 16-17 June 2009.
[8] Parry, Jo-Ellen., Drexhage, J. and Gagnon-Lebrun, F. (2008). Adaptation in a Post-2012. Climate Regime," in John Drexhage, Deborah Murphy and Jenny Gleeson (eds), A Way Forward: Canadian perspectives on post-2012 climate policy, IISD. http://www.iisd.org/pdf/2007/a_way_forward.pdf. Accessed on 13th November, 2014.

[9] Heeks, R. (2010). 'Coherent ICT-for-Development Policies', paper presented at the workshop Policy Coherence in the Application of Information and Communication Technologies for Development, Organization for Economic Co-operation and Development (OECD) and info-Dev, Paris, France, 10-11 September. $\quad$ www.oecd.org/dataoecd/18/8/43762187.pdf Accessed on 19th December, 2015.

[10] Prasad, L., and Heeks, R. (2011). ICT Enabled Development of Capacity for Climate Change Adaptation, Centre for Development Informatics, University of Manchester http://www.niccd.org/PantHeeksClimateChangeAdaptationIC Ts.pdf. Accessed on 15th November, 2014

[11] Karanaisos, S. (2011). New and Emergent ICTs and Climate Change in Developing Countries Centre for Development Informatics, University of Manchester, Manchester. http://www.niccd.org/KaranasiosClimateChangeEmergentICT s.pdf. Accessed on 13th November, 2014.

[12] Mohammad, U.M., Abdur-rahman, M.D., Kazi A. and Rajatheva, M. A. P. (2005), ICT Based Sustainable Rural Business Opportunities in Developing Countries",In American Journal of Applied Sciences, Vol. 2, No. 8, pp. 1256-1260.

[13] UNFCCC (2007). Assessing Climate Change Impacts and Vulnerability: Making Informed Adaptation Decisions, United Nations Framework Convention on Climate change (UNFCCC),

http://unfccc.int/files/adaptation/application/pdf/11unf051 nww-was-web[1].pdf. Accessed on $22^{\text {nd }}$ December, 2015

[14] World Telecommunication Development Conference, Valletta, Malta (1998). Resolution 8: "Telecommunication support for the protection of the environment." http://www.itu.int/ITUD/conferences/wtdc/1998/VAP.html. Accessed on 2nd November, 2014.

[15] World Telecommunication Development Conference, Istanbul, Turkey (2002). Recommendation 7: "Role of telecommunication and information technologies in the protection of the environment." http://www.itu.int/ITU$\mathrm{D} / \mathrm{cyb} / \mathrm{app} / \mathrm{docs} / \mathrm{Rec} 007$.pdf. Accessed on 2nd November, 2014.

[16] World Telecommunication Development Conference, Doha, Qatar (2006). Resolution 54: "Information and communication technology applications." http://www.itu.int/ITUD/cyb/app/docs/wtdc_resolution_54.pdf. Accessed on 2nd November, 2014. 